\title{
Relationship of Serum Procalcitonin, C-reactive Protein, and Lactic Acid to Organ Failure and Outcome in Critically III Pediatric Population
}

\author{
Imran Siddiqui, Lena Jafri, Qalab Abbas ${ }^{1}$, Ahmed Raheem, Anwar UI Haque ${ }^{1}$ \\ Departments of Pathology and Laboratory Medicine and 'Paediatrics and Child Health, Aga Khan University, Karachi, Pakistan
}

\section{Abstract}

Objective: To evaluate the clinical and prognostic utility of procalcitonin (PCT), C-reactive protein (CRP), and lactic acid in children admitted to the Pediatric Intensive Care Unit (PICU) of a university teaching hospital. Materials and Methods: Medical records of children (1 month-16 years) tested for serum PCT at the time of admission in the PICU of our hospital from July 1, 2013, to January 15, 2015, were reviewed. Within $24 \mathrm{~h}$ of admission, the Pediatric Risk of Mortality Score, blood cultures, white blood cell count, neutrophil counts, serum CRP, plasma lactic acid, and PCT were noted. Patient outcome was assessed at hospital discharge, and the patients were divided into nonsurvivors and survivors. Results: A total of 167 children being admitted to the PICU were enrolled. The median age of the study population was 3 years ( $0-16$ years), with $58.6 \%$ being males. Nonsurvivors had significantly higher lactic acid $(4.7 \mathrm{mmol} / \mathrm{L}[2.07-7.6] ; P<0.05)$ than that of the survivors $(2 \mathrm{mmol} / \mathrm{L}[1.3-3] ; P<0.05)$. In addition, nonsurvivors $(94.4 \% ; P<0.05)$ had greater incidence of multiple organ dysfunction syndrome (MODS) than that of the survivors $(38.05 \% ; P<0.05)$. Binary logistic regression showed age, MODS, and lactic acid to be associated with mortality. Conclusions: This study found that in comparison to PCT and CRP, high plasma lactic acid levels are associated with the development of all-cause MODS and worse outcome in critically ill children admitted in PICU. Prediction of prognosis based on the lactic acid alone may contribute to improve patient management, but further studies are required to endorse our findings.

Keywords: Critical care, death, intensive care units, procalcitonin, prognosis, sepsis

\section{INTRODUCTION}

Early recognition and timely management of pediatric sepsis is challenging for the pediatric intensivist. ${ }^{[1-3]}$ Sepsis remains the leading cause of mortality in children admitted in the Pediatric Intensive Care Units (PICUs) in Pakistan as well as around the world. ${ }^{[4-7]}$ Delay in the diagnosis and management results in rapid progression to circulatory collapse, multiple organ dysfunction syndrome (MODS), and eventually death. ${ }^{[8,9]}$ Continuing high rates of morbidity and mortality in PICU due to infections dictate the need for biomarkers to determine the prognosis of critically ill children at admission. ${ }^{[3,10]}$

Conventionally, diagnosis of sepsis was based on clinical signs and symptoms of sepsis, such as fever, tachycardia, and tachypnea, supported by cultures. More recently, sepsis biomarkers have been used. Currently, most commonly used biomarkers to identify sepsis and predict outcome are lactic acid and C-reactive protein (CRP) ${ }^{[11]}$ Lactic acid levels have

\begin{tabular}{|l|l|}
\hline \multicolumn{2}{|c|}{ Access this article online } \\
\hline Quick Response Code: & Website: \\
\hline & www.ijccm.org \\
\hline & \\
\hline
\end{tabular}

been used as a biomarker for tissue hypoxia and anaerobic metabolism, and it is the most widely utilized sepsis biomarker indicating organ dysfunction. ${ }^{[12]}$ Investigators have reported that persistent hyperlactatemia serves as the predictor of poor outcome in critically ill children suffering from sepsis. ${ }^{[13]}$ However, factors associated with sepsis such as liver failure or mitochondrial dysfunction may also cause false elevation of lactic acid. CRP is a marker of acute inflammatory response rather than of infection and is nonspecific. However, it may be useful in determining sepsis severity and its progression. ${ }^{[14]}$ CRP has also been shown to have a poor predictor of mortality

Address for correspondence: Dr. Lena Jafri, Department of Pathology and Laboratory Medicine, Aga Khan University Hospital, Stadium Road, Karachi, Pakistan. E-mail: lena.jafri@aku.edu

This is an open access article distributed under the terms of the Creative Commons Attribution-NonCommercial-ShareAlike 3.0 License, which allows others to remix, tweak, and build upon the work non-commercially, as long as the author is credited and the new creations are licensed under the identical terms.

For reprints contact: reprints@medknow.com

How to cite this article: Siddiqui I, Jafri L, Abbas Q, Raheem A, Haque AU. Relationship of serum procalcitonin, C-reactive protein, and lactic acid to organ failure and outcome in critically ill pediatric population. Indian J Crit Care Med 2018;22:91-5. 
compared to other biomarkers in pediatric population. ${ }^{[15]}$ Another promising marker in clinical use since the last decade is serum procalcitonin (PCT). PCT is a peptide precursor of the hormone calcitonin. ${ }^{[16]}$ The level of PCT rises in a response to a proinflammatory stimulus, especially of bacterial origin. ${ }^{[17,18]}$ In addition to its release during bacterial infection, PCT is also closely related to the severity of systemic inflammation and has a reliable kinetics of induction and elimination. ${ }^{[19]}$ It can, therefore, be used to monitor the course of systemic inflammation and guide the physician in therapeutic decision-making. ${ }^{[20,21]}$ Few studies have addressed serum PCT levels in relation to hospital mortality, and we wish to evaluate this association of increased PCT with morbidity and mortality in children admitted in the ICUs. ${ }^{[22,23]}$ Biomarkers to diagnose sepsis may facilitate early recognition and intervention. Serum biomarkers to determine the prognosis of critically ill children at admission to the PICU or during the stay in PICU constitute a clinical necessity. As the clinical course and pathophysiology of sepsis is also influenced by patient age, it is expected that diagnostic accuracy of certain biomarkers are age specific and may show differences when considering neonates and children as compared to adult patients. We conducted this study to evaluate the association and the prognostic value of PCT, CRP, and lactic acid in children admitted to the PICU of our hospital to test the hypothesis that higher plasma concentrations would be associated with increased prediction of morbidity and mortality risk in critically ill children.

\section{Materials and Methods}

\section{Study design and setting}

This observational study was conducted on patients in the PICU of our hospital. Medical records of children (1 month-16 years) tested for serum PCT at the time of admission in PICU from July 1, 2013, to January 15, 2015, were reviewed. Exemption from the institute's ethical review committee (ERC) was sought (ERC identification number: 3453-Pat-ERC-15), and anonymity of the participants was maintained by coding the medical record numbers with study identifications.

\section{Data collection}

Medical charts of the participants were reviewed to note their demographics, primary diagnosis, comorbidities, length of stay in PICU, and outcome (survived or expired) at the time of discharge from hospital. In addition, the Pediatric Risk of Mortality (PRISM III-24) Score was assessed during the first $24 \mathrm{~h}$ of care in PICU [Figure 1]. Laboratory parameters noted were blood cultures, white blood cell counts, neutrophil counts, serum CRP, plasma lactic acid, and serum PCT, all analyzed on day 1 of PICU admission. The initial PCT result in all patients was on the day of PICU admission. MODSs were defined as per the International Pediatric Sepsis Consensus Conference. ${ }^{[24]}$

Procalcitonin, C-reactive protein, and lactic acid assays All samples were analyzed in the Section of Chemical Pathology, Department of Pathology and Laboratory Medicine,

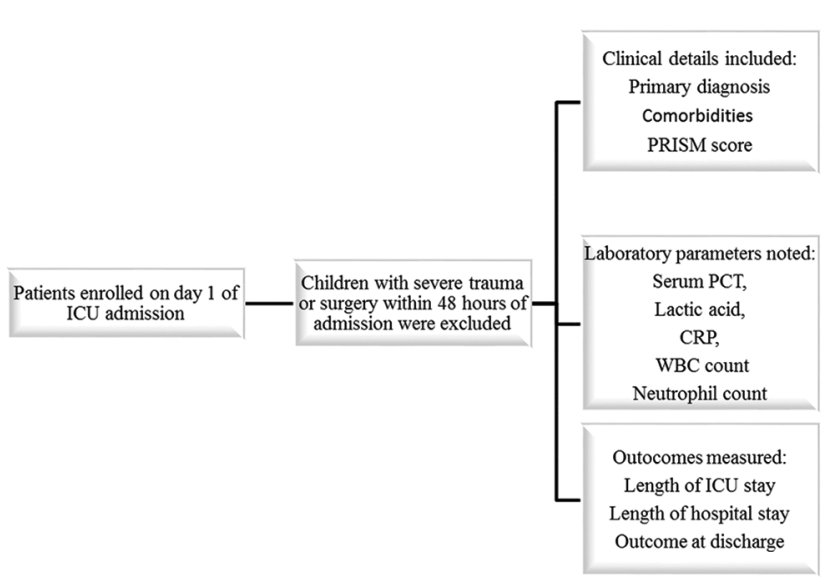

Figure 1: Methodology of patient recruitment and data collection. It is the flow diagram of patients' enrollment and details of data collection of the current study. PCT: Procalcitonin; CRP: C-reactive protein; WBC: White blood cell count

Aga Khan University Hospital, Stadium Road, Karachi, Pakistan. The PCT analysis was performed by Elecsys BRAHMS PCT electrochemiluminescence immunoassay on Cobas E-170 by Roche Diagnostics, Germany. For quality control, two levels of BRAHMS PreciControl were used with each batch of analysis. Lower detection limit of the assay was $0.02 \mathrm{ng} / \mathrm{ml}$ and upper detection limit was $100 \mathrm{ng} / \mathrm{ml}$. Results were determined via a calibrator curve which was instrument specific generated by 2-point calibration and a master curve provided via the reagent barcode. The analyzer automatically calculated the PCT concentration of each sample. Plasma lactic acid was measured by photometric lactate oxidase enzymatic method on ADVIA 1800 chemistry system, by Siemens. Values of lactic acid were expressed in $\mathrm{mmol} / \mathrm{L}$. Serum CRP was measured by latex-enhanced immunoturbidimetric method on ADVIA 1800 chemistry system, by Siemens. For quality control, three levels of internal quality control materials were used with each batch of analysis. During the study period, the College of American Pathologists proficiency testing survey for PCT, CRP, and lactic acid was also run and was acceptable.

\section{Statistical analysis}

The data were analyzed using Statistical Package for the Social Sciences version 19 (Armonk, NY: IBM Corp). The continuous variables with normal distribution were expressed as means \pm 2 standard deviation and were compared using the Student's $t$-test, whereas continuous variables with an asymmetric distribution were expressed as median and the respective interquartile range (IQR) and were compared using the nonparametric Mann-Whitney U-test, for independent samples. Patient outcome was assessed at the time of discharge from hospital, and the patients were divided into nonsurvivor and survivor groups. Between-group differences were tested using the Chi-square test for categorical data and MannWhitney's U-test for continuous. $P<0.05$ was considered statistically significant and $P<0.001$ as highly significant. 


\section{RESULTS}

A total of 167 children admitted to the PICU were enrolled. The median age of the study population was 3 years $(0$ 16 years), with $58.6 \%$ being males. Patients' characteristics are summarized in Table 1 . In $26.9 \%$ of patients, the primary diagnosis was cardiovascular disease, while $19.7 \%$ had pneumonia or bronchiolitis, $11.3 \%$ suffered from sepsis or septic shock, $10.1 \%$ from central nervous system (CNS) infections and $10.1 \%$ had CNS disease, $5.3 \%$ had gastrointestinal disorders, $0.6 \%$ kidney disease and $15.5 \%$ suffered from miscellaneous causes. Out of the total, $76.8 \%$ were admitted through emergency, $19.9 \%$ from wards, and $3.3 \%$ from operation rooms. All 167 patients had blood culture within $48 \mathrm{~h}$ of admission and were reported positive in 34 patients $(20 \%)$. The overall median PRISM score was 4 (IQR 10-0) while the median PCT, lactic acid, and CRP are summarized in Table 1. PCT level $>2 \mathrm{ng} / \mathrm{ml}$ was observed in $113(67.6 \%)$ patients.

The median PICU length of stay was 3 days (range 1-18 days). In total, 167 patients who were admitted to the PICU during the study period were divided into two groups according to the outcome: nonsurvivor group $(n=54)$ and survivor group $(n=113)$. On discharge, $66.7 \%$ of the children survived. Table 2 summarizes the descriptive comparison between the two groups.

No significant differences were found for age, and the proportion of males was higher in the nonsurvivor group. Nonsurvivors had higher lactic acid $(P<0.05)$ and greater incidence of MODS $(P<0.05)$ than the survivors. Among the biomarkers, only plasma levels of lactic acid were significantly higher in nonsurvivors compared to that of survivors (4.7 [7.6-

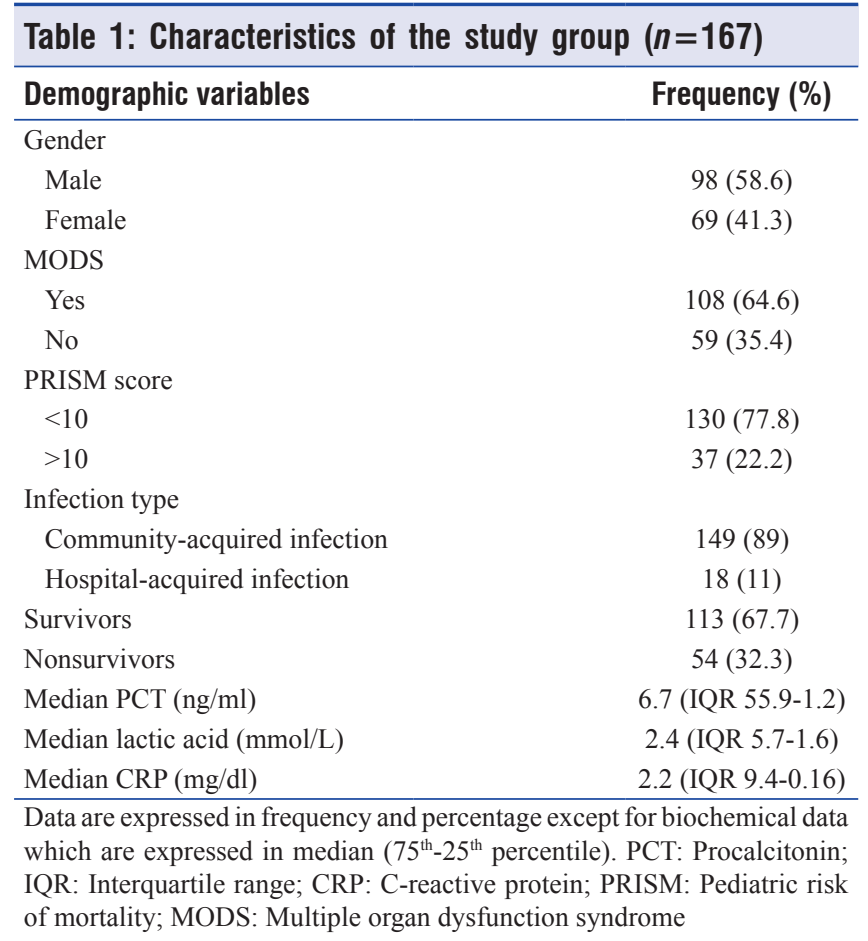

2.07] vs. 2.0 [3.0-1.3] ng/ml; $P<0.001$ ) [Figure 2]. To determine variables associated with mortality, binary logistic regression analysis was done and only lactic acid was associated with mortality $(P<0.05)$.

We identified a higher PRISM Score of $>10$ upon admission to the PICU as a prognostic marker for hospital survival in critically ill patients (hazard ratio 4.623, 95\% confidence interval [CI] 1.86-11.45; $P=0.02$ ). As shown in Table 3, the onset of MODS was higher in patients with greater CRP and lactic acid concentrations. Among the nonsurvivors, majority (94.4\%) had MODS (median PCT: 7.9, CI: $1-51.8 ; P<0.01$ ), whereas in the survivors, $38.05 \%$ had onset of MODS (median PCT: 6.2 , CI: $58.8-1.2 ; P<0.01)$.

\section{Discussion}

Sepsis remains a major cause of morbidity and mortality in children. The use of predictive and prognostic biomarkers has the potential to improve early recognition and timely intervention of patients with sepsis leading to improved outcomes. Assessment in this study revealed that lactic acid has a better discriminative ability than PCT or CRP in predicting mortality in critically ill patients admitted to PICU.

Serum PCT, CRP, and lactic acid levels rise in response to infection and high levels have been found to correlate with the severity of infection, development of MODS, and worse outcome in various studies, but data from PICU are scarce and variable. ${ }^{[25-27]}$ Most earlier studies on the potential utility of PCT in the setting of sepsis have focused on its diagnostic value, rather than prognostic value. ${ }^{[28]}$ Studies evaluating the prognostic utility of PCT show conflicting results. Dahaba et al. also reported no association of PCT levels and mortality in their postoperative critically ill patients. ${ }^{[29]}$ Han et al. showed that increasing PCT levels were associated with persistent bacterial infections and development of MODS, but their study

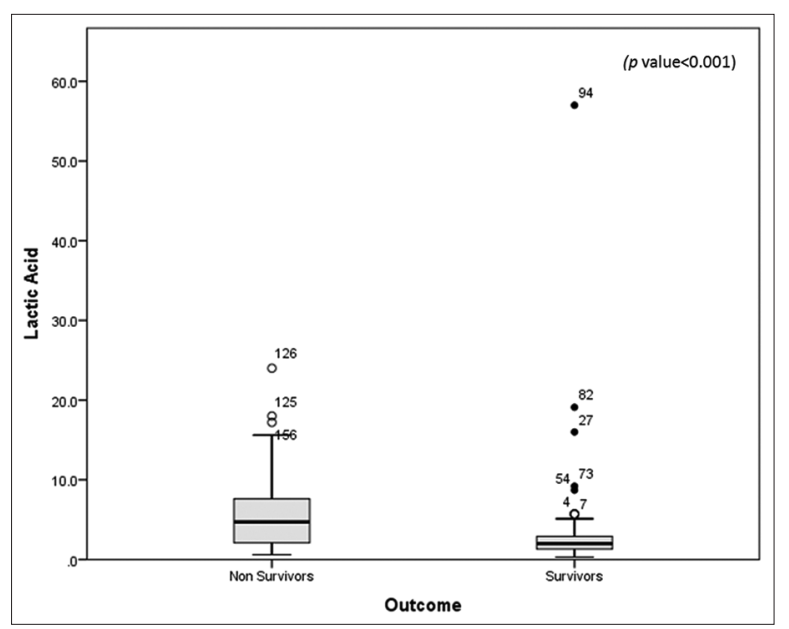

Figure 2: Comparison of lactic acid (in $\mathrm{mmol} / \mathrm{L}$ ) between survivors and nonsurvivors. Data are presented as box plots with median lines, 25- and 75-percentile boxes, and 10- and 90-percentile error bars. The circles represent the outliers 
Table 2: Comparison of baseline characteristics and physiological and laboratory parameters on Intensive Care Unit admission between survivors and nonsurvivors $(n=157)$

\begin{tabular}{|c|c|c|c|}
\hline Study variables & Survivors (n=113), $n$ (\%) & Nonsurvivors ( $n=54), n$ (\%) & $P$ \\
\hline Age in months (range) & $30(84-5.5)$ & $50.5(99-10.2)$ & 0.20 \\
\hline Males & $64(56.6)$ & $33(61.1)$ & 0.57 \\
\hline \multicolumn{4}{|l|}{ Admission source } \\
\hline ED & $75(63.3)$ & $41(75.9)$ & 0.26 \\
\hline Ward & $20(17.6)$ & $10(18.5)$ & \\
\hline OR & $5(4.4)$ & 0 & \\
\hline Median PRISM score & $3(0-9)$ & $5.5(0.75-12.2)$ & 0.08 \\
\hline MODS & $43(38.05)$ & $51(94.4)$ & $<0.01$ \\
\hline Blood culture positive & $17(11.3)$ & $13(8.6)$ & $<0.01$ \\
\hline Median length of ICU stay & $3(5-2)$ & $3(5-2)$ & 0.34 \\
\hline Median length of hospital stay & $10(17-6.5)$ & $9(4.75-16.2)$ & 0.21 \\
\hline PCT value category $>100 \mathrm{ng} / \mathrm{ml}$ & $7(6.1)$ & $10(18.5)$ & 0.49 \\
\hline \multicolumn{4}{|l|}{ PCT $(\mathrm{ng} / \mathrm{ml})$ category } \\
\hline$<10$ & $63(38)$ & $31(19)$ & 0.92 \\
\hline$<30$ & $10(6)$ & $5(03)$ & \\
\hline$<50$ & $7(4)$ & $4(02)$ & \\
\hline$<70$ & $12(7)$ & $4(02)$ & \\
\hline$<90$ & $10(6)$ & $3(02)$ & \\
\hline$\geq 100$ & $11(7)$ & $7(04)$ & \\
\hline Median PCT (ng/ml) & $6.2(58.8-1.2)$ & $7.9(51.8-1.1)$ & 0.81 \\
\hline Median lactic acid (mmol/L) & $2(3-1.3)$ & $4.7(7.6-2.07)$ & $<0.001$ \\
\hline Median CRP (mg/dl) & $1.8(7-0.1)$ & $2.4(10.6-0.2)$ & 0.44 \\
\hline Median WBC $\left(\times 10^{9} / \mathrm{L}\right)$ & $10.6(15.1-7.6)$ & $12.1(17.6-8.7)$ & 0.10 \\
\hline Median neutrophils (\%) & $54(73.7-44)$ & $57.0(74.2-37.7)$ & 0.42 \\
\hline
\end{tabular}

Data is expressed in median $\left(75^{\text {th }}-25^{\text {th }}\right.$ percentile), $P$ values were calculated by Mann-Whitney U-test or Fisher's exact test. ED: Emergency department; OR: Operating room; ICU: Intensive Care Unit; PCT: Procalcitonin; CRP: C-reactive protein; WBC: White blood cell count; PRISM: Pediatric risk of mortality; MODS: Multiple organ dysfunction syndrome

\begin{tabular}{|c|c|c|c|}
\hline \multirow[t]{2}{*}{ Biochemical markers } & \multicolumn{2}{|c|}{ Median $\left(75^{\text {th }}-25^{\text {th }}\right)$} & \multirow[t]{2}{*}{$P$} \\
\hline & MODS present & MODS absent & \\
\hline CRP (mg/dl) & $3(11.9-0.3)$ & $0.5(4.8-0.1)$ & $<0.001$ \\
\hline PCT value (ng/ml) & $8.6(62.2-1.2)$ & $5.1(31.9-1.2)$ & 0.17 \\
\hline Lactic acid (mmol/L) & $3.2(6-1.9)$ & $1.75(2.5-0.9)$ & 0.03 \\
\hline
\end{tabular}

did not show the prognostic value of PCT. ${ }^{[19]}$ On the other hand, Meng et al. in their study from adult ICU showed that serum PCT levels $>10 \mathrm{ng} / \mathrm{ml}$ at the time of admission were associated with all-cause short-term mortality $(P<0.05) \cdot{ }^{[30]}$ A prospective study on 81 pediatric patients with suspected sepsis showed that high PCT level was a good predictor of mortality. ${ }^{[31]}$ Similarly, Magrini et al. showed that PCT level variations in their patients with local and generalized infections were highly predictive of in-hospital mortality. ${ }^{[32]}$ Only plasma lactic acid which is a marker for tissue hypoxia in our study was found to be significantly associated with mortality as compared to PCT. Our study shows that high CRP and lactic acid and not serum PCT levels were associated with the development of MODS. This could be due to poor tissue perfusion and MODS in critically ill children. Casado-Flores et al. showed that PCT levels $>10 \mathrm{ng} / \mathrm{ml}$ were associated with MODS in children with meningococcal infections. ${ }^{[33]}$ Preliminary results in an observational study in children, younger than 19 years of age $(n=239)$, with sepsis also showed high lactic acid levels at initial presentation to be associated with progression to organ dysfunction and critical illness. ${ }^{[34]}$

Several limitations of this study merit consideration. This is a single-center, observational study with limited sample size. Patient inclusion was based on medical charts, and only children with suspicion of infections whose PCT levels were measured were included in the study. Therefore, selection bias cannot be ruled out. Our results need to be validated on prospective larger patient population. Finally, we have performed an observational study that does not allow drawing any conclusion concerning therapeutic interventions.

\section{Conclusions}

In the present study, lactic acid appeared to be a more accurate prognostic biomarker associated with the development of all-cause MODS and worse outcome in critically ill children admitted in PICU. Our study findings in PICU patients suggest 
that the prognostic value of plasma lactic acid is likely to be greater in the critically ill, but prospective studies are required to address the true added value of plasma lactic acid in PICU and its cost implications. Similar studies on pediatric population from critical care areas are scarce and additional investigations are required to validate these findings more definitively.

\section{Financial support and sponsorship}

Nil.

\section{Conflicts of interest}

There are no conflicts of interest.

\section{REFERENCES}

1. Lin YJ. The changing characteristics of neonatal sepsis in the neonatal Intensive Care Unit: A never-ending challenge. Pediatr Neonatol 2009;50:83-4.

2. Chiesa C, Panero A, Osborn JF, Simonetti AF, Pacifico L. Diagnosis of neonatal sepsis: A clinical and laboratory challenge. Clin Chem 2004;50:279-87.

3. Randolph AG, McCulloh RJ. Pediatric sepsis: Important considerations for diagnosing and managing severe infections in infants, children, and adolescents. Virulence 2014;5:179-89.

4. Shin YJ, Ki M, Foxman B. Epidemiology of neonatal sepsis in South Korea. Pediatr Int 2009;51:225-32.

5. Engel C, Brunkhorst FM, Bone HG, Brunkhorst R, Gerlach H, Grond S, et al. Epidemiology of sepsis in Germany: Results from a national prospective multicenter study. Intensive Care Med 2007;33:606-18.

6. Bhutta ZA, Naqvi SH, Muzaffar T, Farooqui BJ. Neonatal sepsis in Pakistan. Presentation and pathogens. Acta Paediatr Scand 1991;80:596-601.

7. Rahman S, Hameed A, Roghani MT, Ullah Z. Multidrug resistant neonatal sepsis in Peshawar, Pakistan. Arch Dis Child Fetal Neonatal Ed 2002;87:F52-4.

8. Branco RG, Garcia PC, Garcia JP, Piva JP, Ross-Russell R. Interactions of sepsis, organ dysfunction, and outcome of critically ill children. Am J Respir Crit Care Med 2005;172:1606.

9. Martinot A, Leclerc F, Cremer R, Leteurtre S, Fourier C, Hue V, et al. Sepsis in neonates and children: Definitions, epidemiology, and outcome. Pediatr Emerg Care 1997;13:277-81.

10. Dunne WM Jr. Laboratory diagnosis of sepsis? No SIRS, not just yet. J Clin Microbiol 2015;53:2404-9.

11. Sharma D, Farahbakhsh N, Shastri S, Sharma P. Biomarkers for diagnosis of neonatal sepsis: A literature review. J Matern Fetal Neonatal Med. 2017 May 7:1-14. [Epub ahead of print].

12. Yan HP, Lu XL, Qiu J, Liu PP, Zuo C, Zhu YM, et al. Value of blood lactic acid in evaluating disease severity and prognosis in children with sepsis. Zhongguo Dang Dai Er Ke Za Zhi 2016;18:506-10.

13. Mikić D, Arsić-Komljenović G, Nozić D, Cućuz M, Dimitrijević R, Vukadinov J, et al. Blood concentrations of lactate, C-reactive protein, and creatinine as early indicators of severity and outcome of sepsis. Med Pregl 2010;63:267-73.

14. Shabuj KH, Hossain J, Moni SC, Dey SK. C-reactive protein (CRP) as a single biomarker for diagnosis of neonatal sepsis: A Comprehensive meta-analysis. Mymensingh Med J 2017;26:364-71.

15. Hisamuddin E, Hisam A, Wahid S, Raza G. Validity of C-reactive protein (CRP) for diagnosis of neonatal sepsis. Pak J Med Sci 2015;31:527-31.

16. Becker KL, Nylén ES, White JC, Müller B, Snider RH Jr. Clinical review 167: Procalcitonin and the calcitonin gene family of peptides in inflammation, infection, and sepsis: A journey from calcitonin back to its precursors. J Clin Endocrinol Metab 2004;89:1512-25.

17. Elbirt D, Frenkel Rubin M, Ergaz D, Sthoeger Z. Procalcitonin - A specific marker for severe bacterial infection and sepsis. Harefuah 2001;140:343-6.

18. Enguix A, Rey C, Concha A, Medina A, Coto D, Diéguez MA, et al. Comparison of procalcitonin with $\mathrm{C}$-reactive protein and serum amyloid for the early diagnosis of bacterial sepsis in critically ill neonates and children. Intensive Care Med 2001;27:211-5.

19. Han YY, Doughty LA, Kofos D, Sasser H, Carcillo JA. Procalcitonin is persistently increased among children with poor outcome from bacterial sepsis. Pediatr Crit Care Med 2003;4:21-5.

20. Harrison M, Collins CD. Is procalcitonin-guided antimicrobial use cost-effective in adult patients with suspected bacterial infection and sepsis? Infect Control Hosp Epidemiol 2015;36:265-72.

21. Westwood M, Ramaekers B, Whiting P, Tomini F, Joore M, Armstrong N, et al. Procalcitonin testing to guide antibiotic therapy for the treatment of sepsis in intensive care settings and for suspected bacterial infection in emergency department settings: A systematic review and cost-effectiveness analysis. Health Technol Assess 2015;19:v-xxv, 1-236.

22. Sauer M, Tiede K, Fuchs D, Gruhn B, Berger D, Zintl F, et al. Procalcitonin, C-reactive protein, and endotoxin after bone marrow transplantation: Identification of children at high risk of morbidity and mortality from sepsis. Bone Marrow Transplant 2003;31:1137-42.

23. Rey C, García-Hernández I, Concha A, Martínez-Camblor P, Botrán M, Medina A, et al. Pro-adrenomedullin, pro-endothelin-1, procalcitonin, C-reactive protein and mortality risk in critically ill children: A prospective study. Crit Care 2013;17:R240.

24. Goldstein B, Giroir B, Randolph A, International Consensus Conference on Pediatric Sepsis. International pediatric sepsis consensus conference: Definitions for sepsis and organ dysfunction in pediatrics. Pediatr Crit Care Med 2005;6:2-8.

25. Giamarellos-Bourboulis EJ, Tsangaris I, Kanni T, Mouktaroudi M, Pantelidou I, Adamis G, et al. Procalcitonin as an early indicator of outcome in sepsis: A prospective observational study. J Hosp Infect 2011;77:58-63.

26. Liu X, Wang DF, Fang Y, Ye WF, Liu S, Lou N, et al. Initial procalcitonin level predicts infection and its outcome in patients with non-Hodgkin lymphoma with febrile neutropenia. Leuk Lymphoma 2015;56:85-91.

27. Wang $\mathrm{C}$, Gao L, Zhang ZG, Li YQ, Yang YL, Chang $\mathrm{T}$, et al. Procalcitonin is a stronger predictor of long-term functional outcome and mortality than high-sensitivity C-reactive protein in patients with ischemic stroke. Mol Neurobiol 2016;53:1509-17.

28. Bartolovic D, Ignjatovic S, Stankovic S, Nada Majkić S. Procalcitonin and other biomarkers of sepsis in newborns in the Intensive Care Unit. EJIFCC 2011;22:24-30.

29. Dahaba AA, Hagara B, Fall A, Rehak PH, List WF, Metzler H, et al. Procalcitonin for early prediction of survival outcome in postoperative critically ill patients with severe sepsis. Br J Anaesth 2006;97:503-8.

30. Meng FS, Su L, Tang YQ, Wen Q, Liu YS, Liu ZF, et al. Serum procalcitonin at the time of admission to the ICU as a predictor of short-term mortality. Clin Biochem 2009;42:1025-31.

31. Bustos BR, Padilla PO. Predictive value of procalcitonin in children with suspected sepsis. Rev Chil Pediatr 2015;86:331-6.

32. Magrini L, Travaglino F, Marino R, Ferri E, De Berardinis B, Cardelli P, et al. Procalcitonin variations after emergency department admission are highly predictive of hospital mortality in patients with acute infectious diseases. Eur Rev Med Pharmacol Sci 2013;17 Suppl 1:133-42.

33. Casado-Flores J, Blanco-Quirós A, Nieto M, Asensio J, Fernández C. Prognostic utility of the semi-quantitative procalcitonin test, neutrophil count and $\mathrm{C}$-reactive protein in meningococcal infection in children. Eur J Pediatr 2006;165:26-9.

34. Scott HF, Donoghue AJ, Gaieski DF, Marchese RF, Mistry RD. The utility of early lactate testing in undifferentiated pediatric systemic inflammatory response syndrome. Acad Emerg Med 2012;19:1276-80. 